\title{
Evaluating Ethylene Sensitivity within the Family Solanaceae at Different Developmental Stages
}

\author{
Nichole F. Edelman and Michelle L. Jones ${ }^{1}$ \\ Department of Horticulture and Crop Science, The Ohio State University, Ohio \\ Agricultural Research and Development Center, 1680 Madison Avenue, \\ Wooster, OH 44691
}

Additional index words. abscission, 1-aminocyclopropane-1-carboxylic acid (ACC), epinasty, flower senescence, seedling triple response

\begin{abstract}
The family Solanaceae, which includes both important crop and ornamental species, is generally considered to have high sensitivity to ethylene. Our objectives were to evaluate ethylene sensitivity between accessions with the family Solanaceae and to determine whether similar sensitivity was observed in seedlings and mature plants. For the seedling evaluations, seeds were germinated and grown in the dark on filter paper saturated with 0 or $100 \mu M$ 1-aminocyclopropane-1-carboxylic acid (ACC; the immediate precursor to ethylene). The relative hypocotyl length at $100 \mu \mathrm{M}$ ACC was compared with untreated control $(0 \mu M)$ seedlings. Mature plants were treated with 0 or $10 \mu L \cdot L^{-1}$ ethylene in the dark for $\mathbf{2 4}$ hours. Ethylene responses including flower abscission, flower senescence, and epinasty were observed and quantified. Seedlings and mature plants were classified as having no response, low, medium, or high ethylene sensitivity based on the severity of the ethylene responses observed. Sensitivity differences were observed among seedling, juvenile, and mature plants, and a range of ethylene responses and symptom severity was observed between accessions within a species. The majority of the accessions were classified as medium or high ethylene sensitivity at both the seedling and mature plant stages. Solanum melongena 'Black Beauty' (eggplant) had a low response to ethylene at the seedling stage and a high response at the mature plant stage, whereas Petunia $\times$ hybrida 'Daddy Orchid' had a high response at the seedling stage and a low response at the mature plant stage. Peppers (Capsicum annum), tomatoes (Solanum lycopersicum), and tomatillos (Physalis ixocarpa) exhibited both floral and vegetative symptoms of ethylene damage, whereas calibrachoas (Calibrachoa $\times$ hybrida), eggplants, nicotianas, and petunias exhibited only floral symptoms. The most common floral response to ethylene treatment was flower abscission, which was observed in almost all of the Solanum, Capsicum, and Nicotiana accessions. We consistently observed ethylene-induced epinasty in the genus Capsicum and in all of the Solanum except eggplant. Our results indicated that developmental stage influenced ethylene sensitivity, and there was not a consistent correlation between seedling and mature plant responses within the Solanaceae accessions that we evaluated.
\end{abstract}

Ethylene $\left(\mathrm{C}_{2} \mathrm{H}_{4}\right)$ is a gaseous hormone that is produced by plants during growth and development and in response to environmental

\footnotetext{
Received for publication 20 Dec. 2013. Accepted for publication 26 Feb. 2014

Salaries and research support were provided in part by state and federal funds appropriated to the Ohio Agricultural Research and Development Center, The Ohio State University. Journal Article Number HCS 13-17. Research was funded by the D.C. Kiplinger Endowment and the American Floral Endowment Gus Poesch Fund.

We acknowledge the Ball Horticultural Company (West Chicago, IL), Green Circle Growers (Oberlin, $\mathrm{OH}$ ), Dr. David Francis (The Ohio State University), Dr. Esther Van der Knaap (The Ohio State University), and Dr. Feng Qu (The Ohio State University) for providing plants and seeds. We especially thank Dr. David Francis and Shaun Broderick for assistance with the statistical analyses, Laura Chapin and Eileen Ramsay for assistance with the research and the manuscript, and James Jones for assistance with the figures.

${ }^{1}$ To whom reprint requests should be addressed; e-mail jones.1968@osu.edu.
}

Goto et al., 1999; Serek et al., 1994, 1995; van Doorn, 2001, 2002; Woltering, 1987; Woltering and van Doorn, 1988). A few studies have used the seedling triple response to evaluate differences in ethylene sensitivity between plants (Clark et al., 2001; Edelman et al., 2014; Lanahan et al., 1994). The seedling triple response screen has been extremely successful at identifying ethylene biosynthesis and signaling mutants in tomato (Solanum lycopersicum) and arabidopsis (Arabidopsis thaliana) (Alexander and Grierson, 2002; Binder et al., 2004). In dark-grown seedlings, hypocotyl length decreases at increasing concentrations of ethylene or ACC, the immediate precursor to ethylene. This component of the triple response provides an easy screen for evaluating ethylene sensitivity. Never ripe $(n r)$ tomato mutants were determined to be ethylene-insensitive because seedlings did not exhibit any symptoms of the triple response when grown on media containing ACC (Lanahan et al., 1994). In contrast, ACCtreated wild-type 'Pearson' seedlings exhibited a significant reduction in hypocotyl length. When mature plants were infiltrated with ACC, epinasty was also observed in the wildtype plants but not the $n r$ mutants.

Solanaceae is a relatively large and very diverse family that includes many plants that are highly sensitive to ethylene. The family contains $\approx 90$ genera consisting of 3000 to 4000 species, which include edible, ornamental, and medicinal plants (Bombarely et al., 2011). Solanum melongena (eggplant), Capsicum annum (pepper), Solanum tuberosum (potato), Solanum lycopersicum (tomato), and Physalis ixocarpa (tomatillo) are important food crops, whereas Calibrachoa $\times$ hybrida, Petunia $\times$ hybrida, and the genus Nicotiana include popular ornamentals. Nicotiana, petunia, and tomato are also widely used as model experimental plants for studying development and plant-pathogen interactions (Gerats and Vandenbussche, 2005; Goodin et al., 2008; Wing et al., 1994). Although studies evaluating ethylene sensitivity have been published for multiple Solanaceous plants at the seedling or mature plant stages (Chaabouni et al., 2009; Edelman et al., 2014; Lanahan et al., 1994; van Doorn, 2001, 2002), a more comprehensive screen comparing sensitivity among genera, species, and cultivars within this family has not been conducted.

We have evaluated ethylene sensitivity in 41 different plant accessions. This study included two objectives: 1 ) to identify ethylene sensitivity differences (levels of sensitivity and symptoms) between accessions within the Solanaceae family; and 2) to identify ethylene sensitivity differences at different developmental stages (seedling, juvenile, and mature plants). This research will determine if the seedling hypocotyl elongation assay can be used to predict mature plant sensitivity within the family Solanaceae.

\section{Materials and Methods}

Plant materials. Forty Solanaceous plants, representing six genera, were selected for 
evaluation (Table 1). Plants included wild species and cultivated varieties. Zinnia marylandica 'Double Zahara Fire' (not a member of the family Solanaceae) was included as a negative control, because this plant was known to have little to no response to ACC at the seedling stage or to exogenous ethylene at the mature plant stage (Edelman et al., 2014). For simplicity, all of the plants in these experiments are referred to as accessions. Solanum pimpinellifolium LA1589 seeds were provided by Dr. Esther Van der Knaap (The Ohio State University). Solanum habrochaites LA0407, Solanum lycopersicum var. Cerasiformae accession PI114490, Solanum lycopersicum 'Selección Mallorquín', Solanum lycopersicum 'FL7600', Solanum lycopersicum 'OH8819', Solanum lycopersicum 'OH9242',
Solanum lycopersicum 'OH981067', Solanum pennellii LA0716, and Solanum pimpinellifolium PI128216 seeds were provided by Dr. David Francis (The Ohio State University). Nicotiana tabacum 'Xanthi' seeds were provided by Dr. Feng Qu (The Ohio State University). Calibrachoa $\times$ hybrida cuttings were provided by Green Circle Growers (Oberlin, $\mathrm{OH}$ ), and all other seeds were from the Ball Horticultural Company (West Chicago, IL) or Ivy Garth Seeds \& Plants (Chesterland, $\mathrm{OH}$ ).

Seedling hypocotyl elongation screen. The effect of ACC on seedling hypocotyl length was evaluated for the species listed in Table 1 except calibrachoa, which were available only as vegetative cuttings, and tomato 'Seleccion Mallorquin' and 'OH9492', which had very inconsistent germination rates. Seeds were sown onto sterile filter paper saturated with $1000 \mu \mathrm{L}$ of 0 (control) or $100 \mu \mathrm{M}$ ACC in petri dishes. This concentration was chosen based on previous experiments (Edelman et al., 2014). The petri dishes were sealed with parafilm and incubated in the dark at $23{ }^{\circ} \mathrm{C}$ for 7 to $10 \mathrm{~d}$. There were two treatments (ACC concentrations) consisting of four replicates (plates) with six seeds sown per replicate. The experiment was performed twice, and each trial represented one block. Seedlings were scanned using WinRhizo (Regent Instruments Inc., Canada) imaging software, and hypocotyl lengths were measured using ImageJ software (Abramoff et al., 2004). The hypocotyl length, as a percentage of the control, was calculated for each seedling and averaged

Table 1. Ethylene sensitivity ratings for 41 plant accessions at the seedling and mature plant stages.

\begin{tabular}{|c|c|c|c|c|c|}
\hline \multirow[b]{2}{*}{ Plant accessions } & \multicolumn{2}{|c|}{ Ethylene sensitivity } & \multicolumn{3}{|c|}{ Plant symptom rating } \\
\hline & Seedling $^{z}$ & Mature plant ${ }^{y}$ & Flower abscission & Flower senescence & Leaf epinasty \\
\hline Zinnia marylandica 'Double Zahara Fire' & No response & No response & No response & No response & No response \\
\hline Nicotiana benthamiana & Medium & High & High & Low & No response \\
\hline Nicotiana alata 'Starmaker Appleblossum' & Medium & High & High & Low & No response \\
\hline Nicotiana alata 'Lime Green' & Medium & High & High & Low & No response \\
\hline Nicotiana mutabilis 'Marshmallow' & High & High & High & Low & No response \\
\hline Nicotiana sylvestris 'Only The Lonely' & Medium & Medium & Medium & Low & No response \\
\hline Nicotiana paniculata & Low & Medium & Medium & Low & No response \\
\hline Nicotiana suaveolens & Medium & High & High & No response & No response \\
\hline Nicotiana tabacum 'Xanthi' & Medium & High & High & Low & No response \\
\hline Petunia $\times$ hybrida 'Carpet White' & Medium & High & Low & High & No response \\
\hline Petunia $\times$ hybrida 'Daddy Orchid' & High & Low & Low & Low & No response \\
\hline Petunia $\times$ hybrida 'Dreams Salmon' & High & Medium & Low & Medium & No response \\
\hline Petunia $\times$ hybrida 'Easy Wave Blue' & Medium & Medium & Low & Medium & No response \\
\hline Petunia $\times$ hybrida 'Madness Red' & Medium & High & Low & High & No response \\
\hline Petunia $\times$ hybrida 'Mitchell Diploid' & Medium & Medium & Low & Medium & No response \\
\hline Calibrachoa $\times$ hybrida 'Callie Dark Blue' & $\mathrm{ND}^{\mathrm{x}}$ & High & Low & High & No response \\
\hline Calibrachoa $\times$ hybrida 'Noa Sunrise' & $\mathrm{ND}^{\mathrm{x}}$ & Medium & Low & Medium & No response \\
\hline Calibrachoa $\times$ hybrida 'Million Bells Terra Cotta' & $\mathrm{ND}^{\mathrm{x}}$ & High & Low & High & No response \\
\hline Solanum melongena 'Black Beauty' & Low & High & High & Low & No response \\
\hline Solanum melongena 'Classic' & Medium & High & High & Low & No response \\
\hline Capsicum annum 'California Wonder 300' & Medium & High & High & Medium & Low \\
\hline Capsicum annum 'Yellow Bell' & Medium & High & High & Medium & Low \\
\hline Capsicum annum 'Habanero Big Sun' & No response & Medium & Low & Low & Medium \\
\hline Physalis ixocarpa 'Grande Rio Verde' & Medium & High & Medium & Low & High \\
\hline Solanum lycopersicum 'Beefsteak' & High & High & Low & Low & High \\
\hline Solanum lycopersicum 'Better Boy' & High & High & $\mathrm{ND}^{\mathrm{w}}$ & $\mathrm{ND}^{\mathrm{w}}$ & High \\
\hline Solanum lycopersicum 'Brandywine Pink Potato Leaf' & High & High & $\mathrm{ND}^{\mathrm{w}}$ & $\mathrm{ND}^{\mathrm{w}}$ & High \\
\hline Solanum lycopersicum 'Cherokee Purple' & High & High & High & Low & High \\
\hline Solanum lycopersicum 'Micro Tom' & High & High & High & No response & Medium \\
\hline Solanum lycopersicum 'Super Sweet 100' & High & High & $\mathrm{ND}^{\mathrm{w}}$ & $\mathrm{ND}^{\mathrm{w}}$ & High \\
\hline Solanum lycopersicum 'Tumbler' & Medium & High & High & No response & High \\
\hline Solanum habrochaites LA0407 & High & High & $\mathrm{ND}^{\mathrm{w}}$ & $\mathrm{ND}^{\mathrm{w}}$ & Medium \\
\hline Solanum lycopersicum var. Cerasiforme PI1 14490 & High & Medium & $\mathrm{ND}^{\mathrm{w}}$ & $\mathrm{ND}^{\mathrm{w}}$ & Medium \\
\hline Solanum lycopersicum 'Seleccíon Mallorquín’ & $\mathrm{ND}^{\mathrm{w}}$ & High & $\mathrm{ND}^{\mathrm{w}}$ & $\mathrm{ND}^{\mathrm{w}}$ & High \\
\hline Solanum lycopersicum 'FLA7600' & High & Medium & $\mathrm{ND}^{\mathrm{w}}$ & $\mathrm{ND}^{\mathrm{w}}$ & Medium \\
\hline Solanum lycopersicum 'OH8819' & High & High & $\mathrm{ND}^{\mathrm{w}}$ & $\mathrm{ND}^{\mathrm{w}}$ & High \\
\hline Solanum lycopersicum 'OH9492' & $\mathrm{ND}^{\mathrm{w}}$ & Medium & $\mathrm{ND}^{\mathrm{w}}$ & $\mathrm{ND}^{\mathrm{w}}$ & Medium \\
\hline Solanum lycopersicum 'OH981067' & High & Medium & $\mathrm{ND}^{\mathrm{w}}$ & $\mathrm{ND}^{\mathrm{w}}$ & Medium \\
\hline Solanum pennellii LA0716 & High & No response & $\mathrm{ND}^{\mathrm{w}}$ & $\mathrm{ND}^{\mathrm{w}}$ & No response \\
\hline Solanum pimpinellifolium LA1589 & High & Medium & $\mathrm{ND}^{\mathrm{w}}$ & $\mathrm{ND}^{\mathrm{w}}$ & Medium \\
\hline Solanum pimpinellifolium PI128216 & High & Medium & $\mathrm{ND}^{\mathrm{w}}$ & $\mathrm{ND}^{\mathrm{w}}$ & Medium \\
\hline
\end{tabular}

${ }^{\mathrm{z}}$ Seedling sensitivity ratings were based on percent relative hypocotyl length in response to 1 -aminocyclopropane-1-carboxylic acid (ACC) at $100 \mu \mathrm{M}$ as compared with controls $(0 \mu \mathrm{M})$ and classified as no response (100\% relative hypocotyl length or greater), low ( $80 \%$ to $99 \%$ relative hypocotyl length), medium ( $50 \%$ to $79 \%$ relative hypocotyl length), or high (below $50 \%$ ) ethylene sensitivity.

${ }^{y}$ Overall mature plant sensitivity was determined based on the highest sensitivity rating assigned for flower abscission, flower senescence, or leaf epinasty for each plant accession. Flower abscission and flower senescence symptom sensitivity ratings were determined by the percent response observed $2 \mathrm{~d}$ after treatment with $10 \mu \mathrm{L} \cdot \mathrm{L}^{-1}$ ethylene and classified as no response ( $\left.0 \%\right)$, low ( $1 \%$ to $20 \%$ ), medium ( $21 \%$ to $40 \%$ ), or high (above $\left.40 \%\right)$ sensitivity to ethylene. Leaf epinasty sensitivity ratings were determined by the degree of epinastic curvature, which is defined as the difference in leaf angle at $0 \mathrm{~d}$ when compared with the initial leaf angle measured before treatment with ethylene and classified as no response $\left(0^{\circ}\right.$ change from initial leaf angle $)$, low ( $1^{\circ}$ to $20^{\circ}$ change from initial leaf angle), medium $\left(21^{\circ}\right.$ to $40^{\circ}$ change from initial leaf angle), and high (greater than $40^{\circ}$ change from initial leaf angle) sensitivity to ethylene.

${ }^{x}$ Not determined. Calibrachoa seedling sensitivity was not determined because seeds were not available. Seedling sensitivity for Solanum lycopersicum 'Seleccíon Mallorquín' and 'OH9495' was not determined as a result of inconsistent germination rates.

${ }^{w}$ Floral symptoms were not recorded for these species. 
for each treatment (seedling length/mean control length $\times 100$ ). Seedling ethylene sensitivity classifications were determined based on the percentage of the hypocotyl length at $100 \mu \mathrm{M}$ ACC as compared with control seedlings $(0 \mu \mathrm{M}$ ACC $)$ : no response $=100 \%$ and greater; low $=80 \%$ to $99 \%$; medium $=50 \%$ to $79 \%$; and high $=$ below $50 \%$. This value is referred to as the relative hypocotyl length. We used no response, rather than including an insensitive classification, because these seedlings may have a response at higher concentrations of ACC and therefore they may not be completely insensitive to ethylene.

Plant culture for mature plant screen. Seeds were sown in 128-count plug trays containing Promix (Premier Tech Horticulture Ltd., Canada), grown under constant, fullspectrum fluorescent lights, and fertigated as needed with $100 \mathrm{mg} \cdot \mathrm{L}^{-1}$ nitrogen $(\mathrm{N})$ from $15 \mathrm{~N}-2.2 \mathrm{P}-12.5 \mathrm{~K}$ Peter's Excel Cal-Mag (Everis International BV ICL Fertilizers Co., Dublin, $\mathrm{OH})$. Seedlings were transported to the greenhouse $\approx 3$ weeks after germination. Plants were grown under natural irradiance with supplemental lighting provided by highpressure sodium and metal halide lamps (GLX/GLS e-systems GROW lights; PARsource, Petaluma, CA). The average photosynthetic photon flux was $\approx 225 \mu \mathrm{mol} \cdot \mathrm{m}^{-2} \cdot \mathrm{s}^{-1}$ from 0600 to $1800 \mathrm{HR}$. Average greenhouse temperatures were $22 / 20 \pm 2 / 1{ }^{\circ} \mathrm{C}$ day/night with $49.2 \% \pm 18.1 \%$ relative humidity. After 1 week in the greenhouse, plants were transplanted into 4.5-inch-diameter plastic pots and irrigated by hand as needed, alternating between $150 \mathrm{mg} \cdot \mathrm{L}^{-1} \mathrm{~N}$ from $15 \mathrm{~N}-2.2 \mathrm{P}-12.5 \mathrm{~K}$ Peter's Excel Cal-Mag and $250 \mathrm{mg} \cdot \mathrm{L}^{-1} \mathrm{~N}$ from 20N-4.37P-16.6K Peter's Professional (Everis International BV ICL Fertilizers Co.).

Mature plant ethylene sensitivity screen. Mature plant evaluations were conducted from July 2012 to June 2013 on all of the accessions in Table 1. Plants were placed into 208-L (55 gallon) metal treatment chambers that were sealed with Plexiglas lids and held in a room at $23{ }^{\circ} \mathrm{C}$. Ethylene gas was injected into the chambers to a final concentration of $10 \mu \mathrm{L} \cdot \mathrm{L}^{-1}(\mathrm{ppm})$. This concentration was chosen based on previous experiments (Edelman et al., 2014). Control chambers contained air $\left(0 \mu \mathrm{L} \cdot \mathrm{L}^{-1}\right.$ ethylene $)$. The ethylene concentrations inside the chambers were confirmed regularly using a gas chromatograph with a flame ionization detector (Varian 3800; Agilent, Foster City, CA). The chambers were covered to exclude light, and plants were treated for $24 \mathrm{~h}$. Mature plants were treated at the flowering stage (more than five flowers), except for select commercial and wild tomato accessions that flowered later and were evaluated only for symptoms of leaf epinasty (Table 1). Each evaluation included two ethylene treatments and four replicates (plants) per treatment. The experiment was performed twice, and each experiment represented one block.

The majority of the plants were evaluated for symptoms of flower abscission (drop), flower senescence (wilt), leaf abscission, leaf chlorosis (yellowing), and leaf epinasty (downward curvature) immediately after removal from the chambers $(0 \mathrm{~d})$ and at $1,2,5$, and $7 \mathrm{~d}$ after treatment. Leaf abscission and

leaf yellowing were not observed on any of the plant accessions, so detailed methods are not provided for these evaluations. Ten tomato

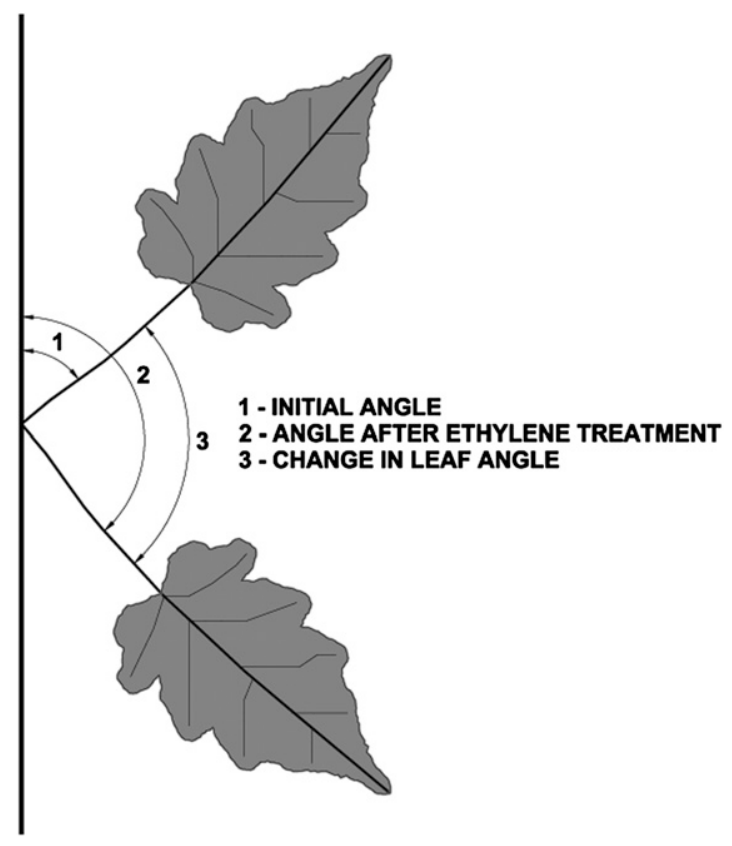

Fig. 1. Measurements conducted to evaluate leaf epinasty. Leaf angles were obtained for the bottom six leaves per plant by measuring the angle from the stem down to the top of the petiole. Initial leaf angles were obtained immediately before ethylene treatment (angle 1). Leaf angles were then measured after ethylene treatment at 0,1 , and $2 \mathrm{~d}$ (angle 2 ) or until the leaf angles returned to within $10^{\circ}$ of the initial angle measurements. The difference in these two measurements was the change in leaf angle or the change in epinastic curvature of the leaf (angle 3).

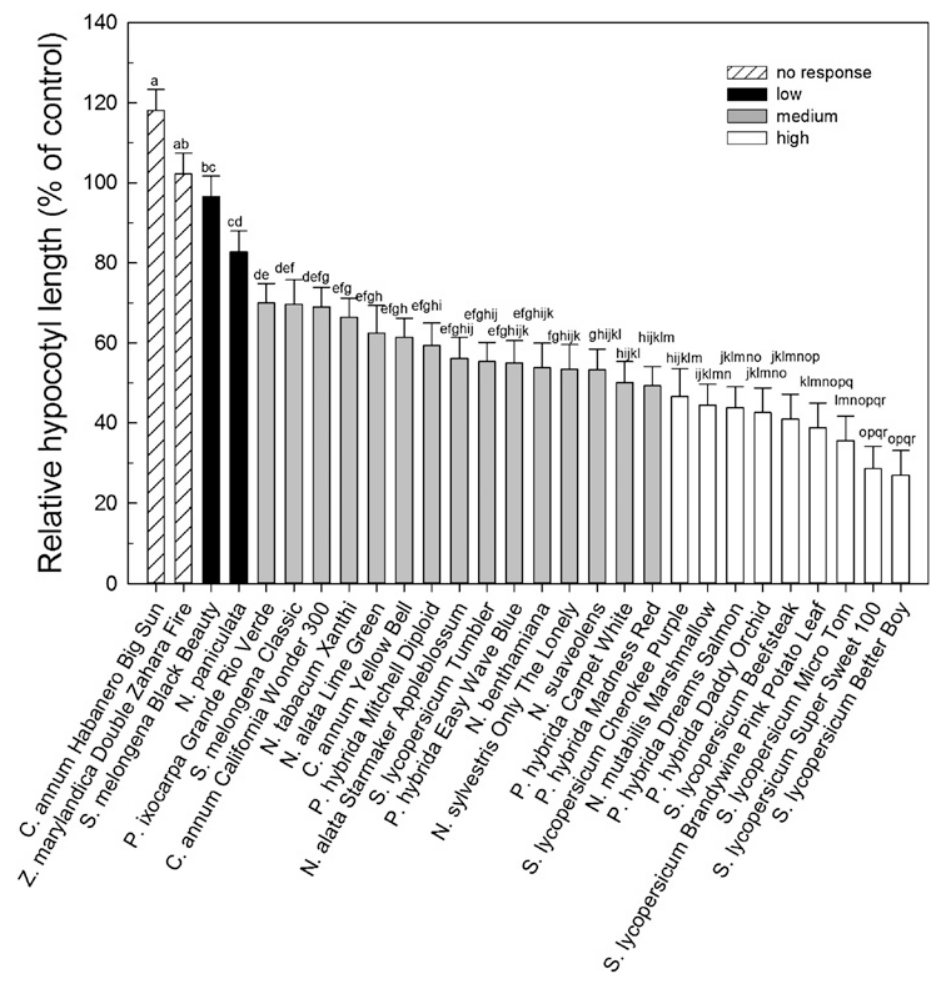

Fig. 2. Seedling hypocotyl elongation screen. Seedlings were evaluated 7 to $10 \mathrm{~d}$ after germination. Bars represent the relative hypocotyl length at $100 \mu \mathrm{M}$ 1-aminocyclopropane-1-carboxylic acid (ACC) expressed as a percentage of the control treatment $(0 \mu \mathrm{M} \mathrm{ACC})$. Error bars represent the SE, and letters above error bars represent significance between accessions, which are based on least significant means test $(\alpha=0.05)$. Plant species were classified as having no response (striped bars), low (black bars), medium (gray bars), or high (white bars) ethylene sensitivity. 
accessions were evaluated only for leaf epinasty (Table 1). The total number of flowers (including open flowers and buds) on each plant was counted before treatment (ethylenetreated and controls) so that the percent flower abscission and flower senescence could be calculated at each time point $(0,1$, and $2 \mathrm{~d})$. Initial leaf angles were measured for each plant before ethylene treatment and then again at 0,1 , and $2 \mathrm{~d}$ after treatment to evaluate leaf epinasty and determine the change in the leaf angle or degree of epinastic curvature. Leaf angles were obtained for the bottom six leaves per plant by measuring the angle between the stem and the top of the petiole (Fig. 1). Measurements were taken until leaf angles returned to within $10^{\circ}$ of the initial angle measurements and plants were considered to be recovered. Sensitivity classifications were assigned for each symptom based on the percent response (flower abscission or flower senescence at $2 \mathrm{~d}$ ) or the change in the leaf angle (leaf epinasty at $0 \mathrm{~d}$ ) after exposure to ethylene. Flower responses at $2 \mathrm{~d}$ after treatment were used for assigning sensitivity classifications because some plants had a delayed response once removed from the chambers, and flower wilting and abscission rates were greatest at $2 \mathrm{~d}$. In contrast, the epinastic response was most severe immediately after the ethylene treatment $(0 \mathrm{~d})$ and many plants had recovered by 1 or $2 \mathrm{~d}$. Ethylene sensitivity classifications for each symptom were as follows: no response $=0 \%$ flower abscission or senescence, $0^{\circ}$ change from initial leaf angle; low $=1 \%$ to $20 \%$ flower abscission or senescence, $1^{\circ}$ to $20^{\circ}$ change from initial leaf angle; medium $=21 \%$ to $40 \%$ floral abscission or senescence, $21^{\circ}$ to $40^{\circ}$ change from initial leaf angle; or high $=41 \%$ to $100 \%$ floral abscission or senescence, greater than $40^{\circ}$ change from initial leaf angle. An overall sensitivity rating for the mature plant was then assigned to each accession based on the highest rated symptom (Table 1).

Evaluation of tomatoes at two developmental stages. In a separate experiment, Solanum lycopersicum (tomato) 'Brandywine Pink Potato Leaf', 'Super Sweet 100', and 'Tumbler' plants were evaluated at two developmental stages (juvenile and mature). Stage 1 juvenile plants were evaluated $\approx 4$ to 5 weeks after sowing, had six to eight leaves, and were not yet flowering. Stage 2 mature plants were evaluated 8 to 9 weeks after sowing, had more than eight leaves, and were flowering. Data were collected only for leaf epinasty. Plants were treated with ethylene and evaluated as described previously.

Statistical analysis. All of the experiments were conducted using a randomized complete block design, and data were analyzed in SAS (Version 9.3; SAS Institute, Cary, NC). For the seedling screen, percentages obtained from hypocotyl measurements were analyzed using PROC GLM (generalized linear model). Significance was determined based on a mean separation using the least significant difference (LSD) test. Data collected from mature plant responses to ethylene were analyzed by PROC GLIMMIX (generalized linear mixed models). Significant means were separated using LSD. All statistical tests used $\alpha=0.05$ for significance.

\section{Results}

Ethylene sensitivity within the Solanaceae family. Screening was conducted on seedlings and mature plants to evaluate ethylene sensitivity differences between accessions within the family Solanaceae. Zinnia marylandica 'Double Zahara Fire' (not a member of Solanaceae) had no response to ethylene at the seedling or mature plant stage (Table 1). It was included for comparison because it has previously been shown to have no response to the ACC or ethylene concentrations used in this study (Edelman et al., 2014). For each accession, control plants were treated with $0 \mu \mathrm{L} \cdot \mathrm{L}^{-1}$ ethylene for $24 \mathrm{~h}$. No significant flower abscission, flower senescence, or leaf epinasty was observed in any of the control plants (data not shown).

Eight accessions of Nicotiana, that included seven different species, were selected for evaluation. Seedling sensitivity ranged from low (N. paniculata) to high (N. mutabilis
'Marshmallow') with relative hypocotyl lengths, which varied from $82 \%$ to $44 \%$ (Fig. 2). The majority of the Nicotiana accessions (six of eight) were classified as having medium ethylene sensitivity at the seedling stage (Table 1). Mature plant accessions were classified as having medium (N. sylvestris 'Only the Lonely' and N. paniculata) and high ( $N$. benthamiana, $N$. alata 'Lime Green', $N$. mutabilis 'Marshmallow', N. alata 'Starmaker Appleblossum', N. suaveolens, and N. tabacum 'Xanthi') ethylene sensitivity (Table 1). Flower abscission was the main symptom of ethylene damage in mature Nicotiana plants (Fig. 3), and very little flower senescence (below 20\%; Fig. 4) was observed. Although N. mutabilis 'Marshmallow' had very little initial response to ethylene (only $2 \%$ flower abscission on $0 \mathrm{~d}$; Fig. 3A), $43 \%$ of the flowers had abscised by $2 \mathrm{~d}$ (Fig. 3B). On Day 2, more than half of the flowers had abscised from N. tabacum 'Xanthi', N. suaveolens, and N. benthamiana (Fig. 3).

At the seedling stage, Petunia $\times$ hybrida 'Dreams Salmon' and 'Daddy Orchid' were classified as having high sensitivity to ethylene with relative hypocotyl lengths that were

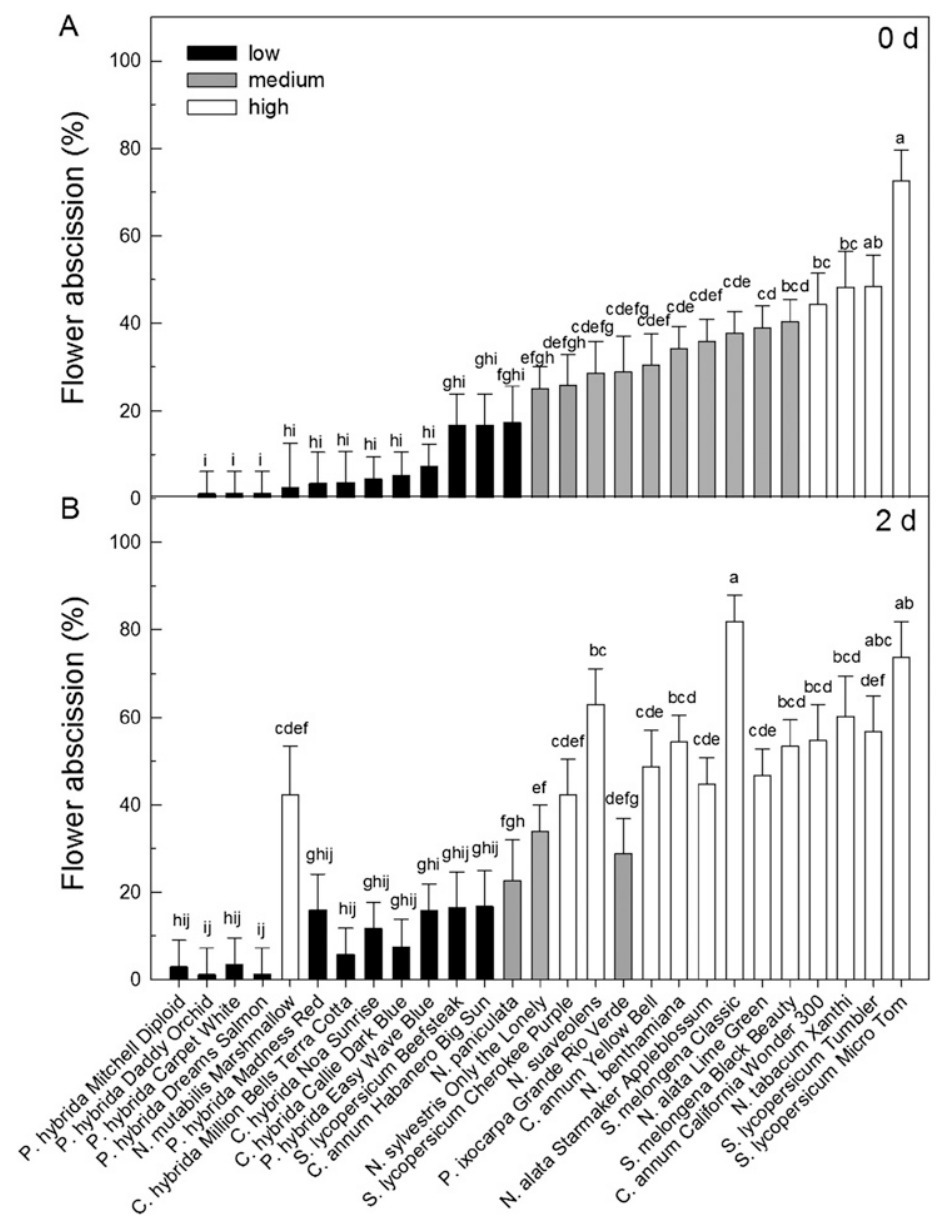

Fig. 3. Flower abscission in mature plants. Rates of flower abscission were determined at $0 \mathrm{~d}(\mathbf{A})$ and $2 \mathrm{~d}$ (B) after treatment with $10 \mu \mathrm{L} \cdot \mathrm{L}^{-1}$ ethylene for $24 \mathrm{~h}$. Bars represent the average percentage of abscised flowers for each accession. Error bars represent the SE, and letters above the error bars represent significance between accessions, which are based on least significant means test $(\alpha=0.05)$. Accessions were classified as having low (black bars), medium (gray bars), or high (white bars) ethylene sensitivity. Accessions with no flower abscission ( $0 \%$ or no response) are not included. 


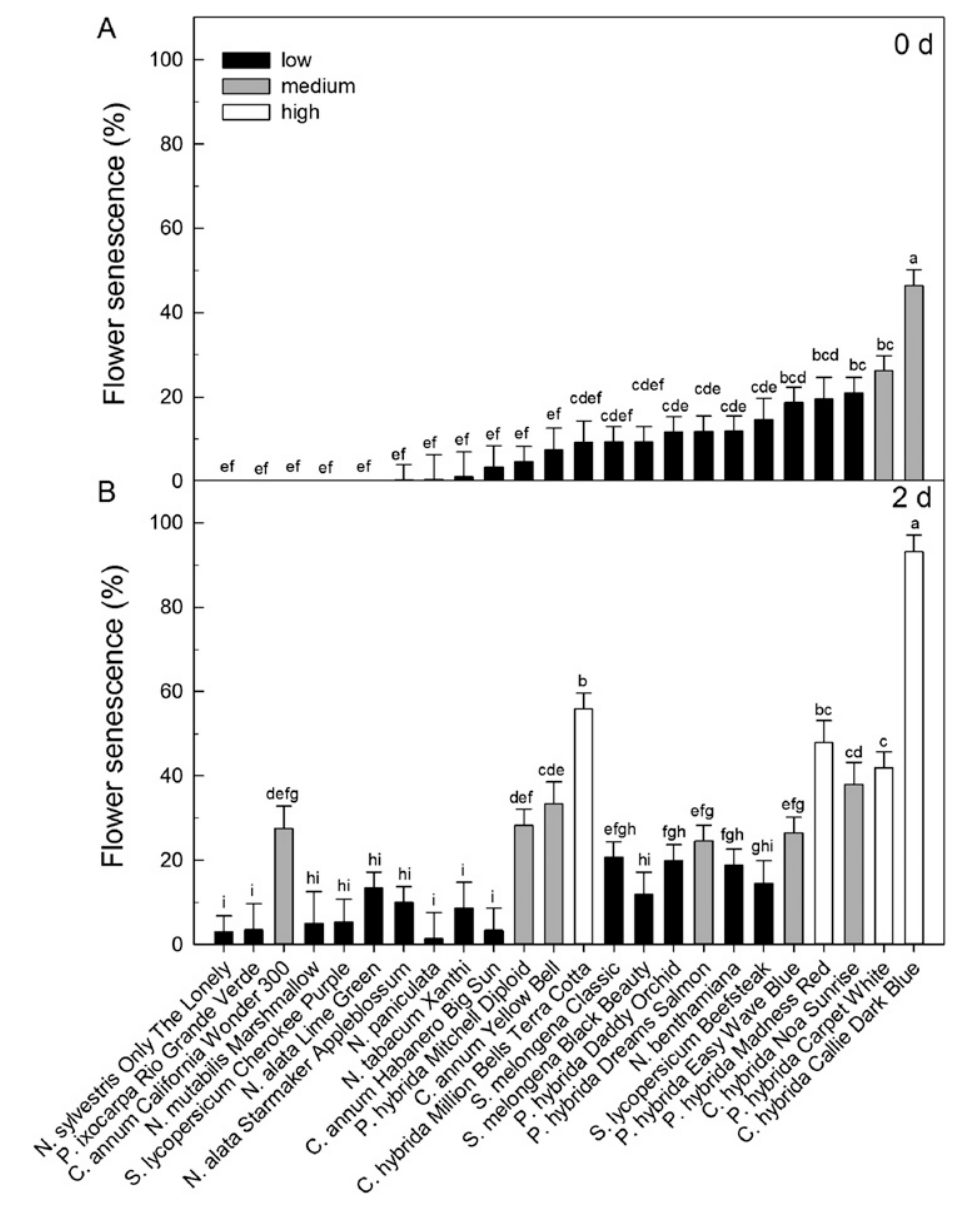

Fig. 4. Flower senescence in mature plants. Rates of flower senescence were determined at $0 \mathrm{~d}(\mathbf{A})$ and $2 \mathrm{~d}$ (B) after treatment with $10 \mu \mathrm{L} \cdot \mathrm{L}^{-1}$ ethylene for $24 \mathrm{~h}$. Bars represent the average percentage of senesced flowers for each accession. Error bars represent the SE, and letters above the error bars represent significance between accessions, which are based on least significant means test $(\alpha=0.05)$. Accessions were classified as having low (black bars), medium (gray bars), or high (white bars) ethylene sensitivity. Accessions with no flower senescence $(0 \%$ or no response) are not included.

$44 \%$ and $43 \%$ of the controls ( $0 \mu \mathrm{M} \mathrm{ACC})$, respectively. Petunia 'Mitchell Diploid', 'Easy Wave Blue', 'Madness Red', and 'Carpet White' were classified as medium sensitivity (Fig. 2). After exposure to $10 \mu \mathrm{L} \cdot \mathrm{L}^{-1}$ ethylene, flower senescence was the main symptom of ethylene damage observed in all six cultivars (Fig. 4). 'Madness Red' and 'Carpet White' were the most sensitive, senescing $48 \%$ and $42 \%$ of flowers at $2 \mathrm{~d}$ (Fig. 4B). These two accessions were assigned an overall sensitivity rating of high. 'Dreams Salmon', 'Easy Wave Blue', and 'Mitchell Diploid' senesced 5\% to $12 \%$ of flowers at $0 \mathrm{~d}$ (Fig. $4 \mathrm{~A}$ ), and $24 \%$ to $28 \%$ of the flowers were senescing by $2 \mathrm{~d}$ (Fig. 4B), resulting in a medium ethylene sensitivity rating. 'Daddy Orchid' had the fewest senescent flowers after ethylene treatment ( $19 \%$ at $2 \mathrm{~d})$ and was the only petunia to receive a low sensitivity rating at the mature plant stage.

Three accessions of Calibrachoa $\times$ hybrida were chosen for evaluation. No data on the ethylene sensitivity of seedlings were obtained because commercial calibrachoa are propagated vegetatively. Like with petunia, flower senescence was the main symptom of ethylene damage observed in mature plants (Fig. 4). The extent of flower senescence between the cultivars at $0 \mathrm{~d}$ (immediately after removal from ethylene) varied from $9 \%$ to $46 \%$ (Fig. $4 \mathrm{~A})$. The percentage of senescing flowers increased over time. Calibrachoa 'Noa Sunrise' had the fewest senescing flowers at $2 \mathrm{~d}(38 \%)$ and received an overall sensitivity rating of medium, whereas 'Million Bells Terra Cotta' and 'Callie Dark Blue' were classified as high ethylene sensitivity as a result of flower senescence rates of $56 \%$ and $93 \%$ ( $2 \mathrm{~d}$ ), respectively (Table 1; Fig. 4B). Only a few flowers abscised (Fig. 3; $6 \%$ to $12 \%$ of the total flowers), and no leaf damage was noted (e.g., leaf chlorosis, abscission, or epinasty).

Seedling ethylene sensitivity of both $S o$ lanum melongena (eggplant) accessions varied from low ('Black Beauty', 97\% relative hypocotyl length) to medium ('Classic', 70\% relative hypocotyl length) (Table 1; Fig. 2). At the mature plant stage, both accessions were assigned an overall sensitivity rating of high based on flower abscission rates, which increased from 0 to $2 \mathrm{~d}$ (Table 1; Fig. 3). 'Classic' exhibited the most severe response, increasing from $38 \%$ to $82 \%$ flower abscission by $2 \mathrm{~d}$, whereas 'Black Beauty' only increased from $40 \%$ to $53 \%$. 'Black Beauty' and 'Classic' had $12 \%$ and $20 \%$ flower senescence at $2 \mathrm{~d}$ (Fig. 4B). Both accessions received a low sensitivity rating for this symptom (Table 1). No leaf epinasty was observed in ethylenetreated eggplants.

Three accessions of Capsicum annum (pepper) including 'Yellow Bell', 'California Wonder 300', and 'Habanero Big Sun' were evaluated, and seedling ethylene sensitivity ranged from no response to medium (Table 1 ). 'Yellow Bell' and 'California Wonder 300' both exhibited a medium response with average relative hypocotyl lengths of $61 \%$ and $69 \%$, respectively. No reduction in hypocotyl length was observed for 'Habanero Big Sun' (no response) when compared with the controls (0 $\mu \mathrm{M}$ ACC) (Fig. 2). Symptoms observed in mature plants after ethylene treatment included flower abscission, flower senescence, and leaf epinasty. 'Habanero Big Sun' also had the lowest ethylene sensitivity at the mature plant stage with flower abscission and senescence rates under $20 \%$ at 2 d (low rating) and only a $29^{\circ}$ change from initial leaf angle at $0 \mathrm{~d}$ (medium rating) (Figs. 3 to 5). 'Yellow Bell' abscised 49\% of the flowers and 'California Wonder 300' abscised 55\% of the flowers by 2 d (high rating; Fig. 3). Both 'Yellow Bell' and 'California Wonder 300' received a medium rating for flower senescence ( $27 \%$ to $33 \%$ flower senescence; Fig. $4 \mathrm{~B}$ ) and a low rating for leaf epinasty (only $9^{\circ}$ to $14^{\circ}$ change in leaf angle at $0 \mathrm{~d}$; Fig. 5A). In general, symptoms of epinasty were greatest on $0 \mathrm{~d}$, immediately on removal from ethylene, and the extent of epinastic curvature in the leaves decreased from 0 to 2 d. 'Habanero Big Sun' and 'California Wonder 300' recovered to within $10^{\circ}$ of their original leaf angles within $1 \mathrm{~d}$ (Fig. 5B), whereas 'Yellow Bell' was fully recovered by $2 \mathrm{~d}$ (Fig. $5 \mathrm{C}$ ).

For Physalis ixocarpa (tomatillo) 'Grande Rio Verde', relative seedling hypocotyl length was $70 \%$, resulting in a seedling ethylene sensitivity classification of medium (Table 1; Fig. 2). 'Grande Rio Verde' was given a mature plant rating of high sensitivity based on leaf epinasty. Tomatillo showed one of the most severe examples of epinastic curvature among the Solanaceae with a $69^{\circ}$ change in epinastic curvature at $0 \mathrm{~d}$ (Fig. 5A). This accession also showed some ethylene-induced flower damage, receiving a low rating for flower senescence $(4 \%)$ and a medium rating for abscission (29\%) (Table 1; Figs. 3 and 4).

Seven commercial cultivars of Solanum lycopersicum (tomato) were evaluated in a screen of seedling and mature plant ethylene sensitivity. At the seedling stage, 'Tumbler' was classified as having medium sensitivity, whereas all other accessions were classified as having high ethylene sensitivity (Table 1). The average relative hypocotyl lengths ranged from 55\% ('Tumbler') to 27\% ('Better Boy') (Fig. 2). Whereas 'Tumbler' was the least sensitive at the seedling stage (Fig. 2), 'Tumbler' and 'Brandywine Pink Potato Leaf' both exhibited the greatest epinastic curvature at the mature plant stage $\left(68^{\circ}\right)$ (Fig. 5A). 'Micro Tom' had the least severe leaf epinasty $\left(28^{\circ}\right)$. The epinastic curvature of the other cultivars varied from $51^{\circ}$ to $65^{\circ}$ immediately after ethylene treatment $(0 \mathrm{~d})$ (Fig. 5A). Rates of 


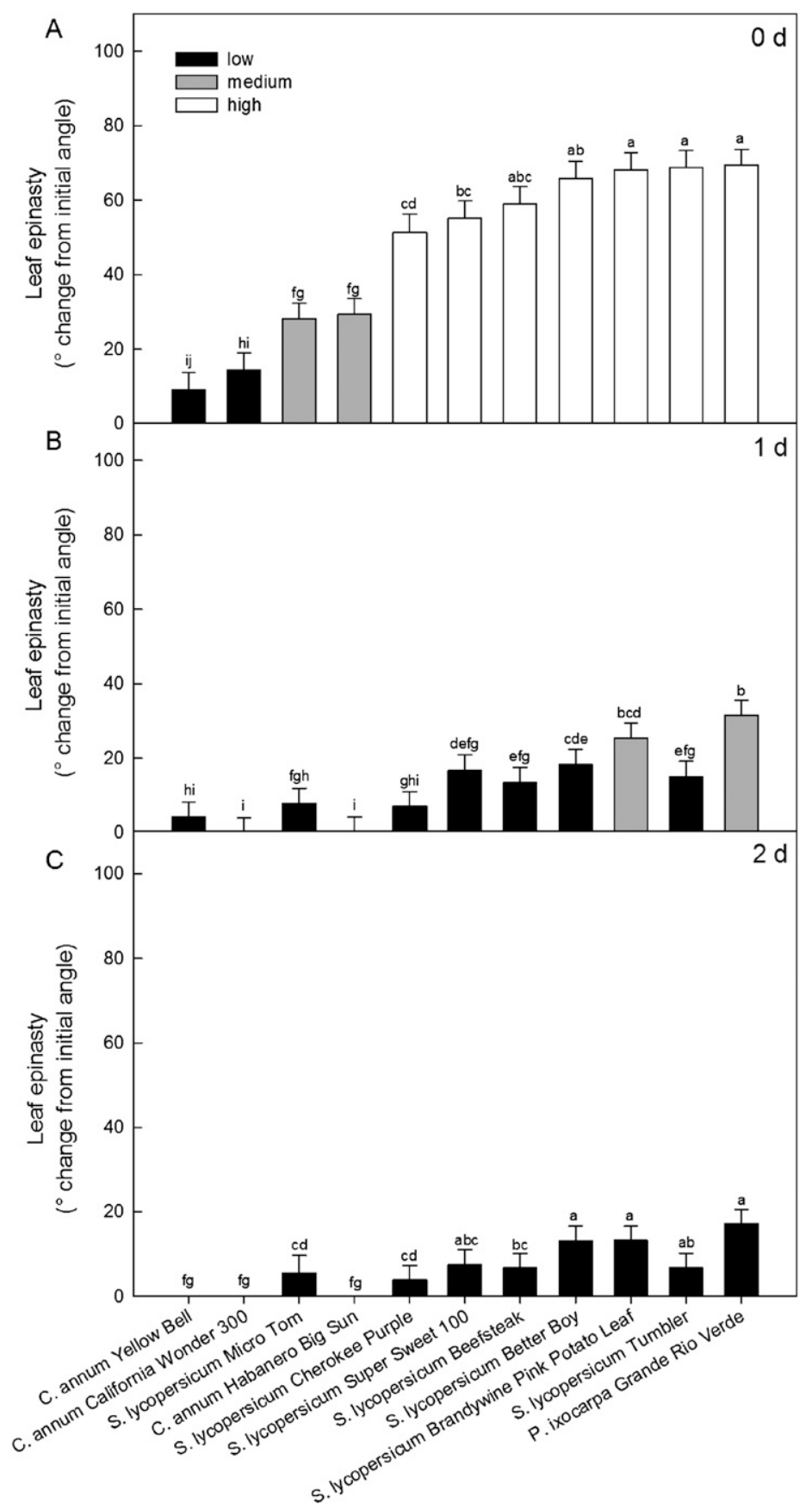

Fig. 5. Leaf epinasty in mature plants. The severity of leaf epinasty was determined at $0 \mathrm{~d}(\mathbf{A}), 1 \mathrm{~d}(\mathbf{B})$, and $2 \mathrm{~d}(\mathbf{C})$ after treatment with $10 \mu \mathrm{L} \cdot \mathrm{L}^{-1}$ ethylene for $24 \mathrm{~h}$. Bars represent the average change in the leaf angle for each accession. Error bars represent the SE, and letters above the error bars represent significance between accessions, which are based on least significant means test $(\alpha=0.05)$. Accessions were categorized as having low (black bars), medium (gray bars), or high (white bars) ethylene sensitivity. Accessions with no epinasty (no change in leaf angle or no response) are not included.

flower abscission at $0 \mathrm{~d}$ ranged from $7 \%$ to $25 \%$ and increased to $14 \%$ to $73 \%$ at $2 \mathrm{~d}$ (Fig. 3). The only accession to exhibit flower senescence at $0 \mathrm{~d}$ was 'Tumbler'. Leaf epinasty was the most severe symptom of ethylene damage and determined the overall sensitivity rating for all mature tomato plants, except 'Micro Tom' (Table 1). 'Micro Tom' received a high sensitivity rating based on flower abscission $(73 \%)$, whereas epinasty $\left(28^{\circ}\right)$ resulted in only a medium sensitivity rating (Figs. $3 \mathrm{~B}$ and 5A). 'Better Boy', 'Brandy Wine Pink Potato
Leaf', and 'Super Sweet 100' plants were much older and larger when they flowered. Flower responses were not evaluated in these accessions so that epinasty measurements could be conducted on plants of similar age (Table 1).

A further evaluation of tomato included additional accessions of $S$. lycopersicum and wild relatives $S$. habrochaites, $S$. pennellii, $S$. pimpinellifolium, and $S$. lycopersicum var. Cerasiformae. Ethylene sensitivity was evaluated using both the seedling and mature plant screens, but epinasty was the only symptom that was quantified in the mature plants. At the seedling stage, relative hypocotyl length varied from $33 \%$ to $21 \%$, and seedling sensitivity was classified as high for all accessions (Fig. 6A). Epinastic curvature varied from $26^{\circ}$ to $55^{\circ}$ at $0 \mathrm{~d}$ for nine of 10 cultivars (classified as medium to high for the symptom of epinasty) (Table 1; Fig. 6B). S. pennellii LA0716 was classified as high sensitivity at the seedling stage and no response at the mature stage with no leaf epinasty observed after treatment with ethylene $(0 \mathrm{~d})$ (Table 1; Fig. 6).

Evaluation of tomatoes at two developmental stages. The symptom of leaf epinasty was further evaluated for three selected cultivars of tomato ('Tumbler', 'Brandywine Pink Potato Leaf', and 'Super Sweet 100') at two stages of development (Stage 1 and Stage 2) (Fig. 7). For all three accessions, the greatest epinastic curvature was observed in the juvenile plants (Stage 1, at 4 to 5 weeks). Stage 1 'Brandywine Pink Potato Leaf' plants exhibited epinastic curvature of $83^{\circ}$, whereas Stage 2 mature plants had epinastic curvature of only $53^{\circ}$. The most extreme effect of plant age on ethylene-induced epinasty was observed in 'Tumbler', which had a difference in epinastic curvature of $70^{\circ}$ between Stage 1 $\left(103^{\circ}\right)$ and Stage $2\left(33^{\circ}\right)$ plants (Fig. 7A-B). At Stage 1, 'Tumbler' would be classified as high sensitivity, whereas the Stage 2 plants would receive a medium sensitivity classification.

\section{Discussion}

Our research was conducted to identify differences in ethylene sensitivity between members of the family Solanaceae and to classify ethylene damage symptoms and sensitivity differences at multiple developmental stages. When seedling and mature plant screens were compared, sensitivity classifications matched in $37 \%$ of the plants. For most Solanaceae accessions, sensitivity at both developmental stages was medium or high. Members of the family Solanaceae are generally reported as ethylene-sensitive, and the family contains many model species used to study ethylene's role in flower senescence, fruit ripening, seedling development, and pathogen responses (Gerats and Vandenbussche, 2005; Goodin et al., 2008; Wing et al., 1994). Seedling and mature plant ethylene sensitivities were opposite (low/no response vs. high or high vs. low/no response) for only three accessions. Eggplant 'Black Beauty' was classified as low sensitivity at the seedling stage and high sensitivity at the mature stage. Petunia 'Daddy Orchid' and $S$. pennellii LA0716 were classified as high ethylene sensitivity at the seedling stage and low or no response at the mature stage. In a previous study of bedding plant species, four of 18 of the plants that were evaluated had the opposite sensitivity classifications when seedling and mature plant sensitivity were compared (Edelman et al., 2014). Although Clark et al. (2001) demonstrated that the seedling 


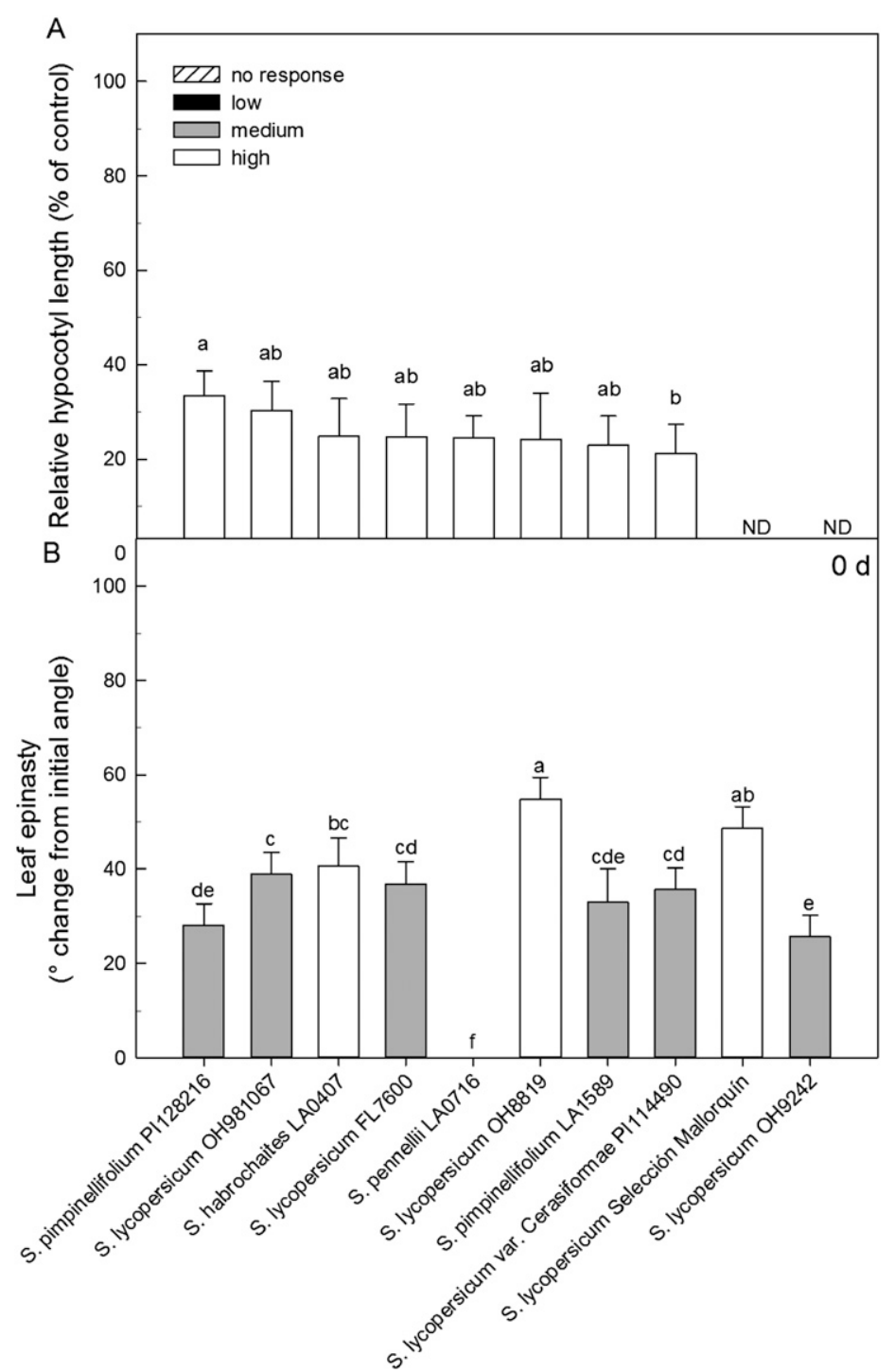

Fig. 6. Comparison of seedling and mature plant responses to ethylene for 10 Solanum accessions. (A) Seedlings were evaluated $7 \mathrm{~d}$ after germination. Bars represent the average relative hypocotyl length at $100 \mu \mathrm{M}$ 1-aminocyclopropane-1-carboxylic acid (ACC) expressed as a percentage of the control treatment $(0 \mu \mathrm{M}$ ACC). (B) Effects of ethylene on accessions exhibiting leaf epinasty on $0 \mathrm{~d}$ after treatment with $10 \mu \mathrm{L} \cdot \mathrm{L}^{-1}$ ethylene for $24 \mathrm{~h}$. Bars represent the degree change at $0 \mathrm{~d}$ from initial leaf angles taken before treatment. Error bars represent the SE, and letters above the error bars represent significance between accessions which are based on least significant means test $(\alpha=0.05)$. Accessions were categorized as having no response (striped bars), low (black bars), medium (gray bars), or high (white bars) ethylene sensitivity. Hypocotyl length not determined (ND) for S. lycopersicum 'Seleccion Mallorquin' and 'OH9242' as a result of inconsistent germination rates. S. pennellii LA0716 had no response $\left(0^{\circ}\right.$ change in leaf angle after ethylene treatment $)$.

hypocotyl elongation screen was a good predictor of mature plant sensitivity in geranium, we found that Viola cornuta 'Sorbet XP Orange', Viola $\times$ wittrockiana (pansy) 'Matrix Lemon', Lobelia erinus 'Regatta Rose', and Salvia splendens 'Red Hot Sally' had very different responses in mature plants and seedlings (Edelman et al., 2014).

Developmental stage (juvenile vs. mature) also influenced the severity of the ethylene response in tomato plants. For two of the three cultivars ('Tumbler' and 'Super Sweet 100'), 4- to 5-week-old juvenile plants (Stage 1) had epinastic curvature that corresponded to a high ethylene sensitivity response, but 8- to 9week-old mature plants (Stage 2) had only a medium response. Contrasting ethylene to the foliage includes leaf abscission, leaf senescence, and epinasty, whereas floral damage includes flower senescence and the abscission of petals or whole flowers. After exposure to $10 \mu \mathrm{L} \cdot \mathrm{L}^{-1}$ ethylene for $24 \mathrm{~h}$, epinasty was the only symptom of vegetative damage that was observed in the 40 Solanaceous accessions that we evaluated. Epinasty is a symptom that has commonly been reported in tomato and is often observed in response to flooding or other abiotic stresses that induce ethylene production in the shoots (English et al., 1995). We consistently observed ethylene-induced epinasty in the genus Capsicum and in all of the Solanum except eggplant ( $S$. melongena). Epinasty was not observed among any accessions of petunia, nicotiana, or calibrachoa. The severity of the epinastic response varied between species and even between accessions within a species like S. lycopersicum.

Tomato is often used as an indicator plant to detect ethylene contamination in commercial greenhouses because it exhibits very obvious epinastic curvature when exposed to low concentrations of ethylene. Even among tomatoes, we observed differences in the severity of the epinasty response. In our evaluation, 'Tumbler', 'Brandywine Pink Potato Leaf', and 'Better Boy' exhibited the greatest leaf epinasty, and they would therefore serve as the best ethylene indicator plants in a greenhouse. We would suggest using juvenile tomato plants and replacing them before they flower.

Differences in ethylene sensitivity were also observed among 10 accessions of wild tomato relatives including $S$. habrochaites, $S$. pennellii, S. pimpinellifolium, and S. lycopersicum var. Cerasiformae. S. pennellii LA0716 had high sensitivity at the seedling stage but had no epinasty response at the mature plant stage. Mature plants exhibited no change in leaf angle after ethylene treatment for $24 \mathrm{~h}$. When S. pennellii LA0716 was treated with $10 \mu \mathrm{L} \cdot \mathrm{L}^{-1}$ ethylene for $72 \mathrm{~h}$, minor epinasty of the petiole was observed (data not shown), indicating that this species is not ethyleneinsensitive. The lack of epinastic response may be attributable in part to the structure of the petioles and stem of LA0716, which are more rigid than typical tomato leaves. We also do not know if LA0716 flowers are sensitive to ethylene, because flower responses were not evaluated in this accession. S. lycopersicum 'OH981067' and 'Seleccion Mallorquin' have mutations in the Nac Nor gene, which confers low ethylene sensitivity and extended shelf life in fruit (Dias et al., 2003; Kopeliovitch et al., 1980). In other studies, fruit from these plants were shown to be less ethylene-sensitive, but leaf evaluations were not reported. During our evaluations, it was shown that this mutation did not result in reduced ethylene sensitivity in other floral or vegetative tissues. These accessions were classified as having medium and high ethylene sensitivity, respectively, based on the epinastic response of the leaves after exposure to ethylene. Because our mature plant screen did not include evaluations of fruit, this screen would not be reflective of fruit shelf life and illustrates the 


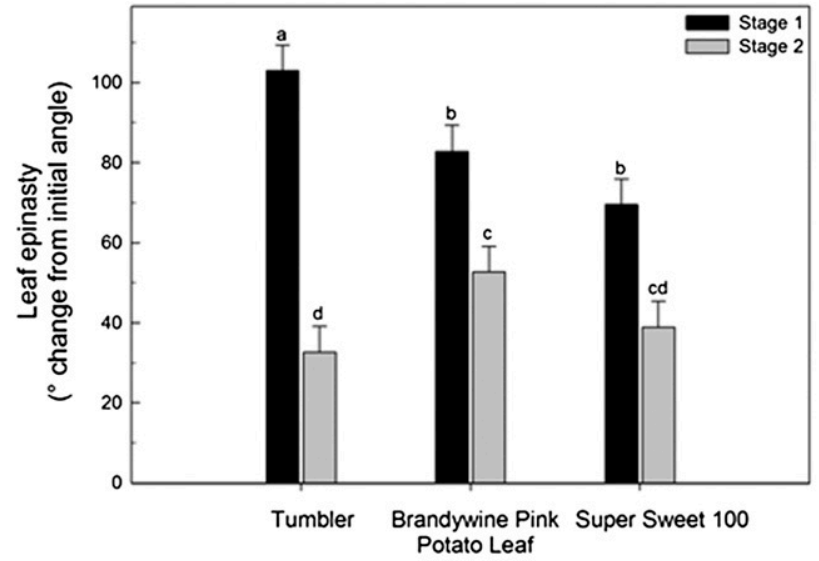

B
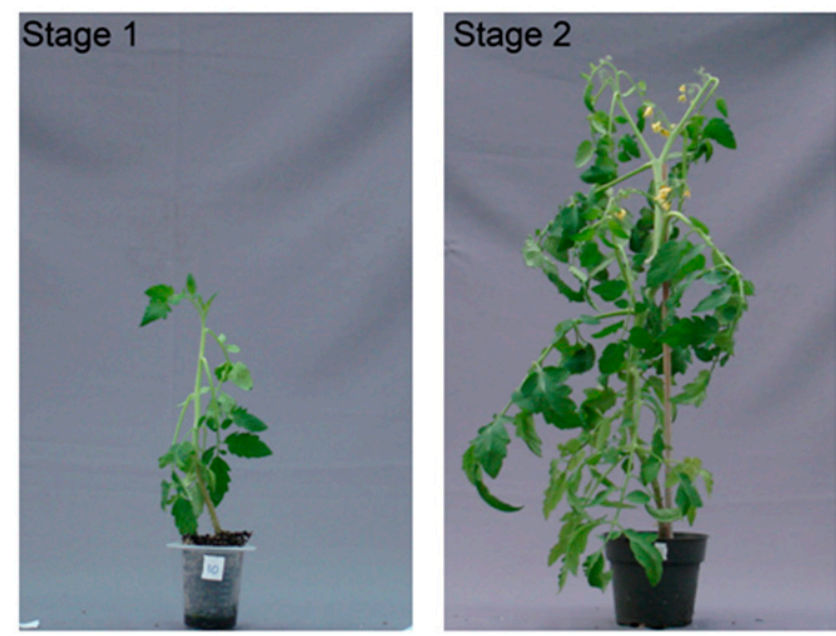

Fig. 7. Effect of plant age on ethylene-induced leaf epinasty in three tomato accessions. (A) The severity of leaf epinasty was determined at $0 \mathrm{~d}$ after treatment with $10 \mu \mathrm{L} \cdot \mathrm{L}^{-1}$ ethylene for $24 \mathrm{~h}$. Bars represent the average change in the leaf angle for each accession. Error bars represent the SE, and letters above the error bars represent significance between accessions which are based on least significant means test $(\alpha=0.05)$. Black bars represent juvenile, Stage 1 plants; grey bars represent mature, Stage 2 plants. Stage 1 plants are 4 to 5 weeks old with six to eight leaves and no flowers, and Stage 2 plants are 8 to 9 weeks old flowering plants with more than eight leaves. (B) Visual observations of leaf epinasty in Stage 1 and Stage 2 S. lycopersicum 'Tumbler' plants at $0 \mathrm{~d}$ after $24 \mathrm{~h}$ treatment with $10 \mu \mathrm{L} \cdot \mathrm{L}^{-1}$ ethylene.

importance of tissue-specific ethylene testing when evaluating ethylene sensitivity.

With the exception of epinastic curvature of leaves, vegetative tissues tend to be less sensitive to ethylene than floral tissues, and higher doses are required to induce leaf senescence and abscission (Kadner and Druege, 2004; Serek and Trolle, 2000; Woltering, 1987). In a comprehensive study of ethylene sensitivity conducted by Woltering (1987), $50 \%$ of foliage and $30 \%$ of flowering plants abscised some leaves. This response was mainly seen when plants were exposed to higher concentrations of ethylene for longer periods of time (i.e., higher doses). In his study, Capsicum annuum (pepper) exhibited leaf abscission, but only after treatment with $15 \mu \mathrm{L} \cdot \mathrm{L}^{-1}$ ethylene for $72 \mathrm{~h}$. The younger leaves were more sensitive to the ethylene treatment and abscised before the older leaves. Ethylene generally promotes the abscission of the oldest leaves on the plant first, but this young leaf abscission response has also been reported in cotton (Morgan and Durham,
1973; Suttle and Hultstrand, 1991). Solanum pseudocapsicum (Jerusalem Cherry) vegetation was more sensitive to ethylene and abscised leaves after only $24 \mathrm{~h}$ of exposure to ethylene (Woltering, 1987). We may have observed leaf abscission in some of our accession if we had included additional treatments that went longer than $24 \mathrm{~h}$, but these responses would still have resulted in a low ethylene sensitivity classification based on our rating system.

Many of the Solanaceous accessions that we evaluated are sold as ornamental or vegetable bedding plants. Bedding plant crops can be exposed to damaging concentrations of ethylene during production, shipping, or retailing, and this causes flower loss as a result of premature senescence or abscission (Jones and Edelman, 2013; Jones and Ling, 2012). It was for this reason that we included the quantification of ethylene-induced flower damage symptoms for the majority of our accessions. In our study, pepper, tomato, and tomatillo exhibited both floral and vegetative symptoms of ethylene damage, whereas calibrachoa, eggplant, nicotiana, and petunia exhibited only floral symptoms. The predominant floral symptom in the family Solanaceae was flower abscission, which was observed in almost all of the Solanum, Capsicum, and Nicotiana accessions. Calibrachoa and petunia were characterized by higher rates of flower senescence, but many of these flowers also abscised once they were fully wilted. Ethylene responses in flowers are fairly consistent within families, and most can be characterized as having either ethylene-induced flower abscission or senescence or ethylene-insensitive senescence (van Doorn, 2001). Other evaluations of flowers within the family Solanaceae have identified abscission as the primary response, but flowers often wilt slightly first and then abscise. This is in contrast to some flowers that abscise only fully turgid corollas with no prior wilting (van Doorn, 2001; Woltering, 1987; Woltering and van Doorn, 1988). Nierembergia sp. and Browallia speciosa, which are important ornamentals within the family Solanaceae, also exhibit ethyleneinduced abscission of flowers and buds (van Doorn, 2001; Woltering, 1987). The severity of ethylene responses in flowers varied between cultivars, as we observed among the petunia and calibrachoa cultivars evaluated in this study. Evaluations of rose, carnation, and kalanchoe have identified varieties that have short shelf lives (or vase lives) as a result of high sensitivity to ethylene and those where an extended flower life is correlated with decreased ethylene sensitivity (Macnish et al., 2011; Serek and Reid, 2000; Serek and Sisler, 2001; Sisler et al., 1996; Woodson and Lawton, 1988).

Although previous evaluations have indicated that mature plant responses between members of a family are often similar (van Doorn, 2001, 2002), this study has illustrated the range of responses and symptom severity observed between plants within the family Solanaceae. Symptoms were more consistent within genera, but the severity of the responses varied between accessions within a species. Observed differences in ethylene sensitivity between developmental stages suggest that the seedling hypocotyl elongation assay would not provide an accurate means of predicting mature plant sensitivity in all Solanaceae. A mature plant screen including both floral and vegetative observations at a consistent developmental stage is required for determining mature plant sensitivity and evaluating differences in sensitivity at the cultivar or species level. This study provides valuable information about which plants within the family Solanaceae are sensitive to ethylene and what symptoms are observed. Plants that experience only leaf epinasty are likely to recover and remain marketable, whereas plants that have lost flowers or leaves as a result of abscission or premature senescence may no longer be saleable. It is therefore most important to the horticulture industry to identify plants where postproduction quality can be protected by treating plants with ethylene inhibitors. We would recommend that any plants exhibiting 
premature senescence or abscission at a medium or high sensitivity rating would benefit from treatment with 1-methylcyclopropene if these plants might be exposed to ethylene during shipping or postproduction handling.

\section{Literature Cited}

Abeles, F.B., P.W. Morgan, and M.E. Saltveit, Jr. 1992. Ethylene in plant biology. $2^{\text {nd }} \mathrm{Ed}$. Academic Press, San Diego, CA.

Abramoff, M.D., P.J. Magalhaes, and S.J. Ram. 2004. Image processing with ImageJ. Biophotonics Intl. 11:36-42.

Alexander, L. and D. Grierson. 2002. Ethylene biosynthesis and action in tomato: A model for climacteric fruit ripening. J. Expt. Bot. 53:20392055.

Archambault, D.J., L. Xiaomei, K.R. Foster, and T.R. Jack. 2006. A screening test for the determination of ethylene sensitivity. Environ. Monit. Assess. 115:509-530.

Binder, B.M., R.C. O'Malley, W. Wang, J.M. Moore, B.M. Parks, E. Spalding, and A.B. Bleecker. 2004. Arabidopsis seedling growth response and recovery to ethylene. A kinetic analysis. Plant Physiol. 136:2913-2920.

Bombarely, A., N. Menda, I.Y. Tecle, R.M. Buels, S. Strickler, T. Fischer-York, A. Pujar, J. Leto, J. Gosselin, and L.A. Mueller. 2011. The Sol genomics network (solgenomics.net): Growing tomatoes using Perl. Nucleic Acids Res. 12 Aug. 2013. <http://solgenomics.net/about/about_ solanaceae.pl $>$.

Burg, S.P. and E.A. Burg. 1965. Ethylene action and the ripening of fruits. Science 148:1190-1196.

Chaabouni, S., B. Jones, C. Delalande, H. Wang, Z. Li, I. Malia, P. Frasse, A. Latche, J.-C. Pech, and M. Bouzayen. 2009. SI-IAA3, a tomato AUX/IAA at the crossroads of auxin and ethylene signaling involved in differential growth. J. Expt. Bot. 60:1349-1362.

Clark, D., C. Dervinis, J. Barrett, and T.A. Nell. 2001. Using a seedling hypocotyl elongation assay as a genetic screen for ethylene sensitivity of seedling geranium cultivars. HortTechnology 11:297-302.

Dias, T.J.M., W.R. Maluf, M.V. Faria, J.A. de Freitas, L.A.A. Gomes, J.T.V. Resende, and S.M. de Asevedo. 2003. Alobaça allele and genotípica backgrounds affect yield and fruit shelf life of tomato hybrids. Scientia Agricola 60:269-275.
Dole, J.M., V. Zenaida, F.L. Fanelli, and W. Fonteno. 2009. Postharvest evaluation of cut dahlia, linaria, lupine, poppy, rudbeckia, trachelium, and zinnia. HortTechnology 19:593600.

Edelman, N.F., B.A. Kaufman, and M.L. Jones. 2014. Comparative evaluation of seedling hypocotyl elongation and mature plant assays for determining ethylene sensitivity in bedding plants. HortScience 49:472-480.

English, J.P., G.W. Lycett, J.A. Roberts, and M.B. Jackson. 1995. Increased 1-aminocyclopropane1-carboxylic acid oxidase activity in shoots of flooded tomato plants raises ethylene production to physiologically active levels. Plant Physiol. 109:1435-1440.

Gerats, T. and M. Vandenbussche. 2005. A model system for comparative research: Petunia. Trends Plant Sci. 10:251-256.

Goodin, M.M., D. Zaitlin, R.A. Naidue, and S.A. Lommel. 2008. Nicotiana benthamiana: Its history as a model for plant-pathogen interactions. Mol. Plant Microbe Interact. 21:10151026.

Goto, R., R. Aida, M. Shibata, and K. Ichimura. 1999. Role of ethylene on flower senescence of Torenia. J. Jpn. Soc. Hort. Sci. 68:263-268.

Jones, M.L. and N. Edelman. 2013. How to prevent ethylene-related losses during the postproduction care and handling of crops. Greenhouse Mgt. 32:38-44.

Jones, M.L. and P. Ling. 2012. Preventing ethylene damage in the production greenhouse. Greenhouse Mgt. 31:45-47.

Kadner, R. and U. Druege. 2004. Role of ethylene action in ethylene production and post storage leaf senescence and survival of pelargonium cuttings. Plant Growth Regulat. 43:187-196.

Knight, L.I., R.C. Rose, and W. Crocker. 1910. Effects of various gases and vapors upon etiolated seedlings of the sweet pea. Science 311:635636.

Kopeliovitch, E., Y. Mizrah, H.D. Rabinowitch, and N. Kedar. 1980. Physiology of tomato mutant alcobaca. Physiol. Plant. 48:307-311.

Lanahan, M.B., H.C. Yen, J.J. Giovannoni, and H.J. Klee. 1994. The never ripe mutation blocks ethylene perception in tomato. Plant Cell 6:521-530.

Macnish, A.J., R.T. Leonard, and T.A. Nell. 2011. Sensitivity of potted foliage plant genotypes to ethylene and 1-methylcyclopropene. HortScience 46:1127-1131.
Morgan, P.W. and J.I. Durham. 1973. Leaf age and ethylene-induced abscission. Plant Physiol. 52:667-670.

Serek, M. and E.C. Sisler. 2001. Efficacy of inhibitors of ethylene binding in improvement of the postharvest characteristics of potted flowering plants. Postharvest Biol. Technol. 23:161-166.

Serek, M., E.C. Sisler, and M.S. Reid. 1994. 1methylcyclopropene, a novel gaseous inhibitor of ethylene action, improves the life of fruits, cut flowers and potted plants. Acta Hort. 394: 337-346.

Serek, M., E.C. Sisler, and M.S. Reid. 1995. Effects of 1-MCP on the vase life and ethylene response of cut flowers. Plant Growth Regulat. 16:93-97.

Serek, M. and L. Trolle. 2000. Factors affecting quality and post-production life of Exacum affine. Sci. Hort. 86:49-55.

Serek, M. and M.S. Reid. 2000. Ethylene and postharvest performance of potted kalanchoe. Postharvest Biol. Technol. 18:43-48.

Sisler, E.C., E. Dupille, and M. Serek. 1996. Effect of 1-methylcyclopropene and methylenecyclopropene on ethylene binding and ethylene action on cut carnations. Plant Growth Regulat. 18:79-86.

Smalle, J. and D. Van Der Straeten. 1997. Ethylene and vegetative development. Physiol. Plant. 100:593-605.

Suttle, J.C. and J.F. Hultstrand. 1991. Ethyleneinduced leaf abscission in cotton seedlings. Plant Physiol. 95:29-33.

van Doorn, W.G. 2001. Categories of petal senescence and abscission: A re-evaluation. Ann. Bot. (Lond.) 87:447-456

van Doorn, W.G. 2002. Effect of ethylene on flower abscission: A survey. Ann. Bot. (Lond.) 89:689-693.

Wing, R.A., H.Z. Zhang, and S.D. Tanksley. 1994. Map based cloning in crop plants. Tomato as a model system: I. Genetic and physical mapping of jointless. Mol. Gen. Genet. 242:681-688.

Woltering, E.J. 1987. Effects of ethylene on ornamental pot plants: A classification. Sci. Hort. 31:283-294.

Woltering, E.J. and W.G. van Doorn. 1988. Role of ethylene in senescence of petals- morphologi$\mathrm{cal}$ and taxonomical relationships. J. Expt. Bot. 39:1605-1616.

Woodson, W.R. and K.A. Lawton. 1988. Ethyleneinduced gene expression in carnation petals. Relationship to autocatalytic ethylene production and senescence. Plant Physiol. 87:498-503. 